\title{
Progressive Facial Asymmetry due to Trigeminal Motor Neuropathy
}

\author{
Johann S. Braun ${ }^{a}$ Katrin Hahn ${ }^{a}$ Hans-Christian Bauknecht $^{\text {b }}$ Eva Schielke $^{c}$ \\ Departments of a Neurology and ${ }^{\mathrm{b}}$ Neuroradiology, Charité University Hospital, Humboldt University, and \\ ${ }^{c}$ Department of Neurology, Vivantes Auguste-Viktoria Hospital, Berlin, Germany
}

Dear Sir,

Facial asymmetry often occurs because of unilateral facial nerve paresis. Here, we report on a HIV-positive patient with progressive facial asymmetry due to unilateral motor trigeminal neuropathy.

\section{Case Report}

A 35-year-old male patient presented with a slowly progressive painless facial asymmetry without sensory disturbances, first noticed 10 years previously. Facial pain, sensory disturbances, sinusitis, or herpes infection were absent. Two years before the onset of facial asymmetry, several teeth had been pulled from the left maxilla and mandible. Five years ago, HIV infection was diagnosed. Opportunistic infections were always absent. In the 2 nd year after HIV diagnosis, treatment with zidovudine, lamivudine and abacavir was initiated, but then switched to didanosine, efavirenz and stavudine in the 4th year, and to didanosine, stavudine, tenofovir and lamivudine in the 5th year. CD4 cell counts and viral load were only available from the last 3 years of infection: CD4 T cells 619,844 and $533 / \mu 1$, viral load 1,790, 11,400 and 500 copies/ml in the $3 \mathrm{rd}$, 4 th and 5 th year, respectively.

Neurological examination revealed massive atrophy of the left temporal and masseter muscle with fasciculation. When opening the mouth, the mandible deviated to the left due to paresis of the left pterygoid muscle. The corneal reflex was positive on both sides. All other neurological systems were regular. In particular, there were no sensory disturbances and no signs of polyneuropathy.

Electromyography did not detect pathological spontaneous activity (most probably due to massive atrophy and chronicity of the process), but showed a single unit interference pattern during maximal voluntary contraction in the left masseter muscle and motor unit action potentials with amplitudes of $4 \mathrm{mV}$. Myopathic changes were absent. Other laboratory parameters were regular, e.g., C-reactive protein, creatine kinase, myoglobin, and blood cell count. A brain magnetic resonance imaging (MRI) scan did not detect any pathology, in particular no lesion of the pons or the mandibular trigeminal nerve branch. However, pronounced left-sided masseteric atrophy was clearly depictable on MRI images (fig. 1).

Altogether, there was massive atrophy and paresis of the left jaw muscles without any sensory facial disturbances, indicating pure motor trigeminal neuropathy. Electromyography confirmed chronic denervation of the left masseter muscle. Lumbar puncture was declined.

\section{Discussion}

The differential diagnosis of motor neuropathy of the trigeminal nerve is challenging. Table 1 summarizes causes of either pure motor trigeminal symptoms or motor trigeminal symptoms in combination with additional neurological symptoms [1-10].

All of these causes were absent in our patient. In addition, there was no evidence of muscle dystrophia based on neurological, electrophysiological and laboratory examinations. A causal relation to HIV infection was not obvious: facial asymmetry has been slowly progressive for 10 years and not aggravated after sexual contact with a HIVpositive man (6 years ago), after HIV diagnosis (5 years ago), or after onset of HIV treatment (4 years ago). However, this does not rule out that HIV infection was present when trigeminal neuropathy manifestations began. HIV-associated myopathy typically causes progressing proximal muscle weakness and myalgia, both of which were absent in our patient.

Isolated unilateral masseter atrophy is also uncommon in inherited neuropathies, such as X-chromosomal bulbospinal neuropathy which typically occurs bilaterally. Atrophy due to inactivity is not likely since most of the teeth were present. Absence of pain, fever and regular C-reactive protein argue against an inflammatory or infectious origin, e.g., myositis or vasculitis. A lesion

\section{KARGER}

Fax +4161306 1234 E-Mail karger@karger.ch www.karger.com www.karger.com/ene
Johann Sebastian Braun, MD

Department of Neurology, Charité University Hospital, Campus Mitte

Schumannstrasse 20-21

DE-10117 Berlin (Germany)

Tel. +49 30450560 102, Fax +49 30450560 932, E-Mail johann.braun@charite.de 

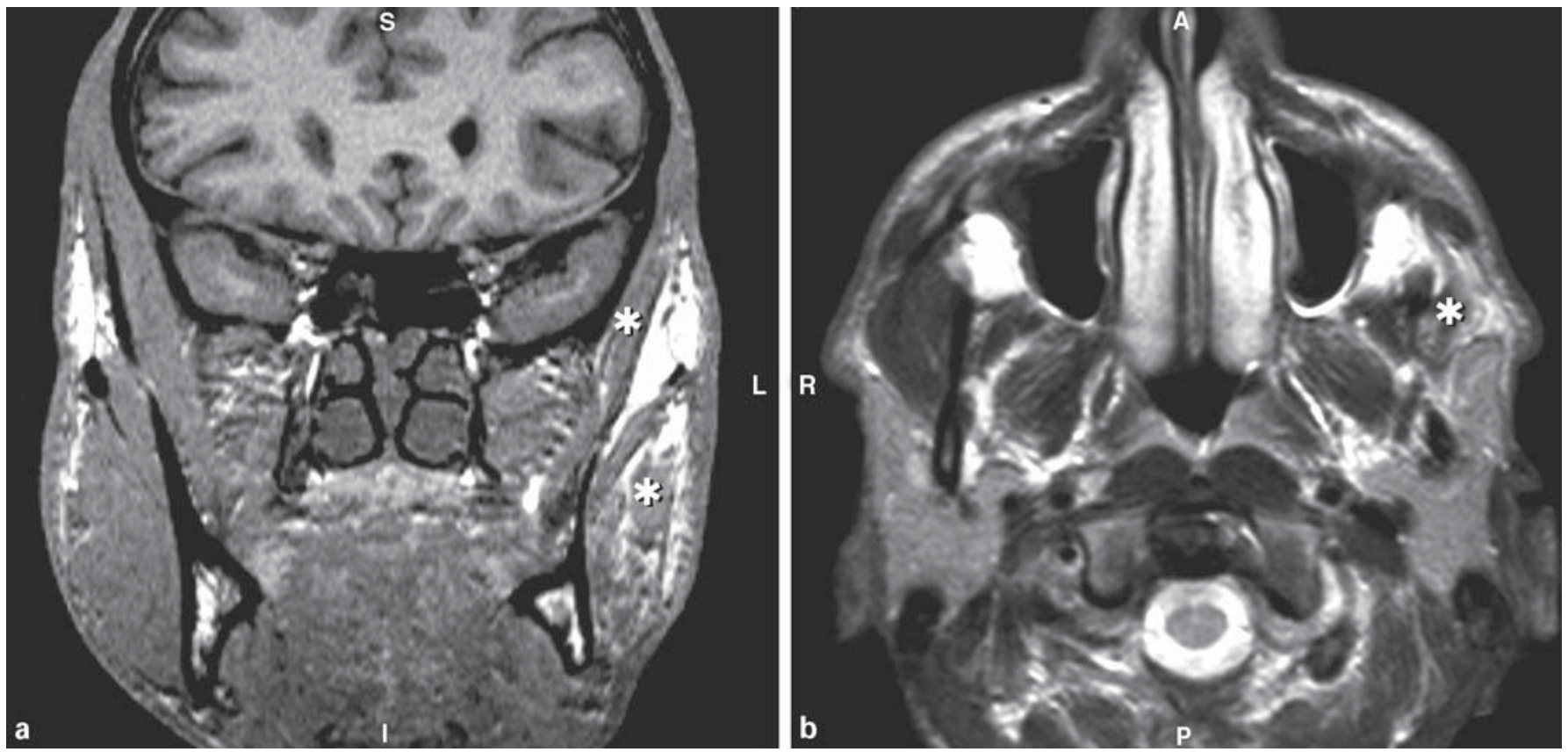

Fig. 1. Unenhanced, coronal $T_{1}$-weighted (a) and axial $T_{2}$-weighted (b) magnetic resonance images, showing pronounced left-sided masseter and temporal muscle atrophy (asterisks) as compared with the contralateral side.

Table 1. Differential diagnosis of trigeminal neuropathy

\begin{tabular}{|c|c|c|}
\hline Causes & Symptoms & Ref. \\
\hline \multicolumn{3}{|l|}{ Autoimmune-inflammatory } \\
\hline Sjogren & $\begin{array}{l}\text { motor or mixed trigeminal symptoms, motor or sensory } \\
\text { or mixed neuropathy }\end{array}$ & 1 \\
\hline Neurofibromatosis & motor trigeminal symptoms & 2 \\
\hline $\begin{array}{l}\text { Chronic inflammatory demyelinating } \\
\text { polyneuropathy }\end{array}$ & motor and sensory trigeminal symptoms & 5 \\
\hline Post-viral-infection autoimmune response & pure motor trigeminal symptoms & 6 \\
\hline \multicolumn{3}{|l|}{ Infectious } \\
\hline Viral infection & pure motor trigeminal symptoms & 3 \\
\hline \multicolumn{3}{|l|}{ Ischemic } \\
\hline Small infarction & motor trigeminal symptoms and mild hemiparesis & 4 \\
\hline \multicolumn{3}{|l|}{ Traumatic } \\
\hline $\begin{array}{l}\text { Head trauma (skull base fracture of the } \\
\text { oval foramen or pontine hemorrhage) }\end{array}$ & pure motor trigeminal symptoms & 7 \\
\hline \multicolumn{3}{|l|}{ Genetic } \\
\hline Developmental origin & pure motor trigeminal symptoms & 8 \\
\hline \multicolumn{3}{|l|}{ Multiple } \\
\hline $\begin{array}{l}\text { Neoplasm, virus, trauma, multiple } \\
\text { sclerosis, Tolosa-Hunt, sarcoidosis, } \\
\text { aneurysm }\end{array}$ & $\begin{array}{l}\text { motor and sensory trigeminal symptoms, partly with } \\
\text { impairment of taste, facial palsy, vestibular insufficiency, } \\
\text { hearing disturbance, hypoglossal palsy cerebellar lesion }\end{array}$ & 9 \\
\hline Syringomyelia, multiple sclerosis & motor trigeminal symptoms, occipitalgia & 10 \\
\hline
\end{tabular}


of the supranuclear trigeminal tract is hardly conceivable due to the bilateral innervation of the trigeminal nuclei. The patient negated craniocerebral injury and surgery of the face. High-resolution cranial MRI did not detect a lesion of motor trigeminal nucleus in the pons or below the oval foramen, e.g., a trigeminal schwannoma. A retrograde Wallerian degeneration (following teeth pulling) of the inferior alveolar nerve up to the motor branching of the mandibular nerve is implausible since sensory function of the tongue (lingualis nerve) and chin (mentalis nerve) were completely intact.

In summary, the facial asymmetry was due to left-sided jaw muscle atrophy and paresis due to pure motor trigeminal neuropathy beginning 2 years after pulling several molars of the left maxilla and mandible. The limitation to unilateral jaw muscles, the absence of pain, regular facial sensation, chronic progression over a period of 10 years as well as the results of MRI, electromyography and blood testing exclude all known differential diagnoses of the pure motor trigeminal neuropathy.

\section{References}

1 Andonopoulos AP, Lagos G, Drosos AA, Moutsopoulos HM: The spectrum of neurological involvement in Sjogren's syndrome. $\mathrm{Br}$ J Rheumatol 1990;29:21-23.

2 Beydoun SR: Unilateral trigeminal motor neuropathy as a presenting feature of neurofibromatosis type 2 (NF2). Muscle Nerve 1993; 16: 1136-1137.

3 Chia LG: Pure trigeminal motor neuropathy. Br Med J 1988;296:609-610.

4 Chiba S, Motoi Y, Noro H, Asakura K, Matsumoto $\mathrm{H}$ : A case of pure trigeminal motor neuropathy. Rinsho Shinkeigaku 1990;30:883887.
5 Cruccu G, Agostino R, Inghilleri M, Innocenti P, Romaniello A, Manfredi M: Mandibular nerve involvement in diabetic polyneuropathy and chronic inflammatory demyelinating polyneuropathy. Muscle Nerve 1998;21:16731679.

6 Kang YK, Lee EH, Hwang M: Pure trigeminal motor neuropathy: a case report. Arch Phys Med Rehabil 2000;81:995-998.

7 Ko KF, Chan KL: A case of isolated pure trigeminal motor neuropathy. Clin Neurol Neurosurg 1995;97:199-200.

8 Parmar SC, Watkinson A, Fieldhouse J: Facial asymmetry with severe unilateral hypoplasia of the muscles of mastication: a report of clinical and electromyographic findings. Br J Oral Maxillofac Surg 1996;34:107-109.

9 Sawamura Y, Tashiro K, Shima K, Moriwaka $\mathrm{F}$, Abe $\mathrm{H}$ : Clinical analysis of trigeminal neuropathy as initial manifestations - an etiological study. No To Shinkei 1988;40:863-868.

10 Takamatsu K, Takizawa T, Miyamoto T: A case of pure trigeminal motor neuropathy. Rinsho Shinkeigaku 1993;33:541-545. 